\title{
Influence of Biodiesel on Base Oil Oxidation as Measured by FTICR Mass Spectrometry
}

\author{
Hugh E. Jones, Diana Catalina Palacio Lozano, Chris Huener, Mary J. Thomas, David J. Aaserud, \\ J. Corinne DeMuth, Mathew P. Robin, and Mark P. Barrow*
}

Cite This: Energy Fuels 2021, 35, 11896-11908

Read Online

ACCESS | Llll Metrics \& More | 国 Article Recommendations | sl Supporting Information

ABSTRACT: Internal combustion engine lubricants are subject to thermooxidative degradation during use and must be designed to withstand oxidation in order to extend their useful life. Understanding the complex chemical process of thermo-oxidative degradation is essential to designing higher performing engine lubricants. In this study base oil samples composed of a Group II base oil, doped with three different levels of biodiesel (B0, B15, and B100), were subjected to benchtop oxidation testing of up to $168 \mathrm{~h}$, which mimics the conditions experienced in an internal combustion engine. The resulting samples were analyzed by Fourier

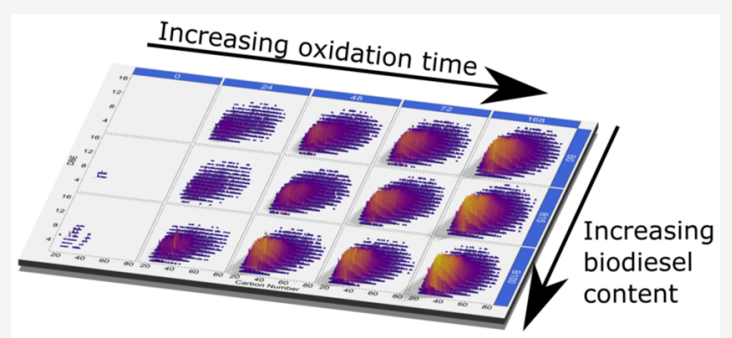
transform ion cyclotron resonance mass spectrometry (FTICR MS) for ultrahigh-resolution characterization to monitor oxidation as a function of time and biofuel content. Both negative-ion nanoelectrospray ionization and positive-ion atmospheric pressure photoionization were utilized. Most of the oxidation products were found to be polyoxygenated species containing 1-8 oxygen atoms, with the number of detected species increasing with oxidation time. Assessment of the maximum carbon number of protonated classes indicated the involvement of oligomerization reactions; additionally, modeling of mean double bond equivalents (DBE) for each protonated class suggests increasing carbonyl content for each particular class with increasing oxidation time. The oxidations of B15 and B100 doped samples were compared to that of B0. B15 samples were found to correspond closely to B0 samples, with a similar number of species detected. B100 samples showed a significant increase in number of species generated at 24-72 h relative to B0 and B15; however, a similar number of species were observed at $168 \mathrm{~h}$ for all samples, indicating a similar level of base oil oxidation at the final oxidation point. FTICR MS is shown to afford new insights into base oil oxidation as a function of time and biofuel content.

\section{INTRODUCTION}

Internal combustion engine oils undergo aging while in use, a major factor of which is thermo-oxidation which leads to the generation of oxidized species such as peroxides, alcohols, aldehydes, ketones, and carboxylic acids. The generation of carboxylic acids causes additional issues in the form of engine corrosion as a consequence of increased acidity. If oxidation is not controlled, the decomposition of the engine oil can result in oil thickening, ${ }^{1-3}$ sludge, and deposit formation. ${ }^{4}$ Excessive oil thickening may eventually lead to pumping failures and oil starvation.

To combat oil aging and to improve the physical and chemical properties of the lubricant oil, modern engine oils are usually a mixture of several different components. The main constituent is the base oil, with additives such as antioxidants and viscosity modifiers added to tune the properties of the lubricant oil to meet performance and service interval requirements.

Base oils can have varying properties depending on their composition. The American Petroleum Institute (API) defines five groups for base oils as shown in Table 1. Groups I, II, and III are produced from petroleum sources via various refining
Table 1. Properties of API Defined Base Oil Groups ${ }^{9}$

\begin{tabular}{cccc} 
API Group & saturate level (\%) & sulfur level (\%) & viscosity index \\
I & $<90$ & $>0.03$ & $80-120$ \\
II & $\geq 90$ & $\leq 0.03$ & $80-120$ \\
III & $\geq 90$ & $\leq 0.03$ & $\geq 120$ \\
IV & \multicolumn{3}{c}{ synthetic poly $(\alpha$-olefin) } \\
V & all others not included in Groups I-IV \\
\hline
\end{tabular}

methods and mainly comprise hydrocarbons, such as alkanes, alkenes, alicyclics, and aromatics. Non-hydrocarbon species can also be present, of which organosulfur compounds are most prevalent compared to nitrogen- and oxygen-containing species. ${ }^{5}$ API Group II and III oils are majority saturates $(\geq 90 \%)$, with a higher percentage of normal-, iso-, and cyclo-

Received: April 22, 2021

Revised: June 22, 2021

Published: July 26, 2021 
paraffins (naphthenes) than solvent refined (Group I) oils, and as such performance and chemical properties of these oils are controlled by the relative abundance and chemistries of saturated species in the base oil. ${ }^{6,7}$ Production capacity for Group II and III oils is growing at the expense of Group I as demand moves to higher-quality and longer-life oils. ${ }^{8}$

The mechanism for the oxidation of hydrocarbons is typically described as a free radical chain process, comprising initiation, chain propagation, chain branching, and termination steps. $^{3,4,7,10}$ The radical chain is initiated by the reaction of dissolved oxygen with hydrocarbon compounds; the hydrocarbon compounds are likely to be either aromatics or unstable heterocyclics. ${ }^{3}$ After the initiators are formed, propagation proceeds through the reaction between highly reactive aliphatic radicals and oxygen, forming hydroperoxides. In the chain branching stage hydroperoxides decompose to alkoxy and hydroxy radicals which further react, typically forming a variety of products such as ketones, aldehydes, alcohols, and carboxylic acids. The main product is typically ketones for paraffins or ketones and aldehydes in the case of benzene derivatives. ${ }^{11}$ The ketone and aldehyde products themselves are readily oxidizable to acids, which in turn can react with alcohol species to form esters. In addition, intramolecular rupture reactions can occur, causing the release of low molecular weight volatile products such as $\mathrm{CO}_{2}, \mathrm{CH}_{2} \mathrm{O}$, and $\mathrm{CH}_{3} \mathrm{OH}$ as well as $\mathrm{H}_{2} \mathrm{O}$. ${ }^{3}$ The final termination step occurs when two free radicals combine. The mechanism ${ }^{12}$ of nonhydrocarbon base oils as well as their degradation products has also been investigated. ${ }^{13,14}$

The oxidation of a fully formulated engine oil can be split into three stages. ${ }^{15}$ In the initial inhibition stage minimal oxidation occurs due to antioxidant action from radical inhibitors or hydroperoxide decomposers; ${ }^{3}$ this stage ends when the antioxidant species are depleted. In the second stage, oxidation is not influenced by antioxidants and oxidation of the hydrocarbon readily occurs. In the last stage, the oxidation rate slows due to increased oil viscosity resulting from the formation of high molecular weight condensed polymeric oxygenated compounds, ${ }^{16}$ limiting the rate of oxygen diffusion into the oil. When applied to base oil alone, without any additives, only the latter two stages are observed; the base oil oxidizes rapidly with a slowing down of the oxidation rate as the viscosity of the oil increases.

One area of concern is fuel dilution of engine lubricant oils, particularly by biodiesel due to the growing trend of moving to higher proportions of biodiesel in diesel fuel blends. Increased fuel dilution occurs due to the higher boiling point of biodiesel, leading to increased engine oil degradation and engine deposit formation. ${ }^{17}$ The presence of biodiesel is known to decrease the oxidative stability of the base oil ${ }^{18}$ with increased oxidation of lubricant oil observed. ${ }^{17,19}$ The oxidation of biodiesel occurs by an initial rapid oxidation of fatty acid methyl esters (FAMEs) to form peroxides which then lead to the formation of other secondary products such as aldehydes, ketones, and acids. $^{20,21}$ Further reactions lead to the eventual formation of polyoxygenated high molecular weight material; such material has been shown to be rich in ester content. ${ }^{20}$

For the development of improved antioxidants, first a detailed characterization of the species present in oxidized base oils is needed, followed by an understanding of the oxidation processes occurring. Mass spectrometry has been previously used for the study of lubricant oils: ${ }^{13,14,30,22-29}$ Fourier transform ion cyclotron resonance mass spectrometry
(FTICR MS) offers the highest resolving power and mass accuracy of ultrahigh-resolution mass spectrometry (UHRMS) techniques and is well suited to the analysis of oxidized base oil. While techniques such as nuclear magnetic resonance (NMR) and Fourier transform infrared spectroscopy (FTIR) can give information about an average molecule occurring in a mixture, FTICR MS can give elemental compositional information to the thousands of individual species occurring within a sample. FTICR MS has previously been used for the analysis of biodiesel oxidation, ${ }^{31}$ crude oil, ${ }^{32-35}$ dissolved organic matter, ${ }^{36,37}$ bio-oils, ${ }^{38-40}$ and other complex mixtures in the field of petroleomics. ${ }^{41}$

Electrospray ionization (ESI) has been previously used when targeting antioxidants in lubricant oil mixtures for degradation studies, as the bulk materials of the oil (hydrocarbon species) are not efficiently ionized by ESI, simplifying the analysis. ${ }^{23,29}$ Additionally, negative-ion ESI is ideal for the analysis of the polar carboxylic acid species produced by the oxidation process. Atmospheric pressure photoionization (APPI) is well suited for the ionization of hydrocarbon molecules such as polycyclic aromatic hydrocarbons (PAHs); as such it can be used to characterize aromatic base-oil hydrocarbon species. Linear alkanes such as paraffins are not efficiently ionized by either APPI or ESI; however, several different ionization sources have been proposed for improved ionization of saturated species such as atmospheric pressure chemical ionization $(\mathrm{APCI})^{28,30}$ or the use of low-temperature plasma (LTP). ${ }^{42}$ Alternative techniques to APPI and ESI such as easy ambient sonic-spray ionization (EASI) have been successfully used for the analysis of biodiesel oxidation. ${ }^{31,43}$

In this study FTICR MS data are used in tandem with conventional analysis, providing further insights into the effect of differing levels of biodiesel upon the oxidation of a Group II base oil. While previous studies have used low resolution methods to investigate oxidation of biodiesel and additives, here we use FTICR MS for ultrahigh-resolution characterization of base oil samples to monitor oxidation as a function of time and biofuel content. This, in turn, provides insights into the oxidation processes and how differing levels of biofuels, which can come into contact with engine oils, can affect the rate of oxidation of the base oils. Group II base oils were selected for this study due to their commercial significance for heavy duty diesel (HDD) engine use. We have characterized a series of oxidized group II base oil samples, produced by a benchtop oxidation testing, with differing levels of biodiesel doping: 0,15 , and $100 \%$ (B0, B15, and B100, respectively). Petroleomics methods were used for the data analysis, which included additional analyses through modeling of the mean DBE and use of Upset plots.

\section{MATERIALS AND METHODS}

Samples. A Group II base oil mixture was produced from two commercial Group II base oils at a $15 \%: 85 \% \mathrm{w} / \mathrm{w}$ ratio to give a final kinematic viscosity measured at $100{ }^{\circ} \mathrm{C}$ (KV100) of $5.84 \mathrm{~mm}^{2} / \mathrm{s}$. Properties for these two base oils are given in Table S1. A KV100 for the base oil in this range is required for the formulation of SAE $5 \mathrm{~W}-30$ and SAE 10W-40 viscosity grade engine oils. SAE 5W-30 and SAE $10 \mathrm{~W}-40$ have a high market share, making the study of this base oil mixture of high commercial importance. Samples with different levels of biodiesel were prepared by the addition of 5 vol \% of a diesel mixture comprising mineral diesel (CEC DF-79-07) and biodiesel (80:20 mix of soybean methyl ester to rapeseed methyl ester). The diesel mixture added to each sample had the following compositions: 
B0 (100\% diesel), B15 (85\% diesel, 15\% biodiesel), and B100 (100\% biodiesel).

The prepared samples were then subjected to a modified benchtop Daimler oxidation test. The test procedure is described in Figure S1. In brief, a $500 \mathrm{~mL}$ three-necked flask equipped with a jacketed coil condenser, and an air inlet set at $10 \mathrm{~L} / \mathrm{h}$, was set up in an oil bath with the temperature set at $160^{\circ} \mathrm{C}$, and $250 \mathrm{~g}$ of oil sample was added with $100 \mathrm{ppm}(158.1 \mathrm{mg})$ of iron(III) acetylacetonate as a catalyst. The oxidation was monitored by samples taken at $0,24,48,72$, and $168 \mathrm{~h}$ time points.

Conventional Analysis. The kinematic viscosity at $100{ }^{\circ} \mathrm{C}$ was measured according to the ASTM D7279 ${ }^{44}$ standard method by using an ISL Houillon viscometer VH1. Initial $\mathrm{pH}(\mathrm{i}-\mathrm{pH})$ was measured at room temperature according to the ASTM D7946 ${ }^{45}$ standard method using a Metrohm 855 autosampler with a Metrohm LL-Solvotrode ( $\mathrm{LiCl}$ salt in EtOH electrode). Oxidation was measured as the FTIR peak height at $1710 \mathrm{~cm}^{-1}$ according to DIN $51453^{46}$ standard method using a PerkinElmer FTIR Spectrum 65 spectrometer.

FTICR MS Analysis. Samples were analyzed with a $12 \mathrm{~T}$ solariX FTICR mass spectrometer (Bruker Daltonik GmbH, Bremen, Germany) coupled to an APPI II ion source operating in positiveion $(+)$ mode and a home-built nano-ESI (nESI) source operating in negative-ion $(-)$ mode.

All samples for APPI analysis were prepared as $0.1 \mathrm{mg} / \mathrm{mL}$ concentration solutions in a 50:50\% v/v mixture of propan-2-ol and toluene (HPLC grade 99.9\%, Honeywell, Bracknell, UK). Samples were infused by using a flow rate of $600 \mu \mathrm{L} / \mathrm{h}$, a drying gas temperature of $280{ }^{\circ} \mathrm{C}$, and a nebulizer temperature of $350{ }^{\circ} \mathrm{C}$. Ions were accumulated for $0.6 \mathrm{~s}$ in the collision cell before being transferred to the ICR cell for detection. Spectra were acquired by coadding 300 broadband mass spectra with a $4 \mathrm{MW}$ data set size with a detection range of $\mathrm{m} / z 202.7-3000$. The value of $\mathrm{m} / z 202.7$ was chosen as it is known that an increased low mass cutoff results in increased resolution for FTMS instruments. ${ }^{41}$ As such, it is beneficial to use a value that is optimal to both observe low $\mathrm{m} / z$ species present in base oil samples and achieve increased resolution.

All samples for nESI analysis were prepared in an 80:20\% v/v mixture of propanol and toluene. The $0 \mathrm{~h}$ samples were prepared at $0.1 \mathrm{mg} / \mathrm{mL}$ concentration; all other samples were prepared by using a concentration of $0.05 \mathrm{mg} / \mathrm{mL}$. Spectra were acquired by coadding 300 broadband mass spectra with a $4 \mathrm{MW}$ data set size with a detection range of $m / z 98.3-1500$.

All mass spectra were internally calibrated in Data Analysis 5.0 (Bruker Daltonik GmbH, Bremen, Germany) with the quadratic mode by using a known abundant homologous series present in the sample. Mass spectra generated by $(-)$ nESI were internally calibrated with $\mathrm{O}_{2}[\mathrm{H}]$ species, and APPI mass spectra were internally calibrated with series of $\mathrm{HC}[\mathrm{H}]$ and $\mathrm{O}_{3}[\mathrm{H}]$ species; calibration mass lists can be found Tables S2 and S3. For both (-)nESI and (+)APPI data a mass accuracy of $<1 \mathrm{ppm}$ allowed assignment of a unique elemental assignment per composition. Three replicate data sets were acquired for B0 samples by (+)APPI $(0,24,48,72$, and $168 \mathrm{~h})$ to enable accurate determination of base oil oxidation trends; all other data sets were acquired once.

Data Analysis. The replicate data sets were processed by using an updated version of the in-house tool Themis, ${ }^{47}$ termed Themis 2.0 , to generate a single data set from each set of (three) replicates containing peaks only present in two or more replicates. Themis additionally removes noise peaks, enabling the assignment of species at much lower signal-to-noise values than possible in a standard mass spectrum, which may go undetected by using standard peak picking and left unassigned.

Composer 1.5.6 (Sierra Analytics Inc., Modesto, CA) was used for elemental compositional assignment with the following constraints: mass error $<1 \mathrm{ppm}$, and the following limits for atoms; APPI: $\mathrm{C}_{4-200}$, $\mathrm{H}_{4-1000}, \mathrm{~N}_{0-2}, \mathrm{~S}_{0-2}, \mathrm{O}_{0-20} ; \mathrm{nESI}: \mathrm{C}_{4-200}, \mathrm{H}_{4-1000}, \mathrm{~N}_{0-2}, \mathrm{~S}_{0-2}, \mathrm{O}_{0-20}$. The root-mean square ppm error was $<0.5 \mathrm{ppm}$ for $(-)$ nESI data and $<0.3 \mathrm{ppm}$ for (+)APPI data sets. Once elemental compositions were assigned, species can be further characterized by carbon number, double bond equivalents (DBE), and heteroatom content. DBE is calculated by the following formula: DBE $=c-h / 2+n / 2+1$, where $c, h$, and $n$ are the numbers of carbon, hydrogen, and nitrogen atoms, respectively. Heteroatom content can be summarized by a class label. For example, $\mathrm{C}_{32} \mathrm{H}_{60} \mathrm{O}_{4}[\mathrm{H}]$ is part of the class $\mathrm{O}_{4}[\mathrm{H}]$, where the $[\mathrm{H}]$ label denotes an even-electron ion, and the absence of this label denotes an odd-electron radical species. DBE values for odd-electron species will have integer values, while even-electron species have halfinteger DBE values. For example, $\mathrm{C}_{32} \mathrm{H}_{60} \mathrm{O}_{4}$ has a DBE value of 3 , while $\mathrm{C}_{32} \mathrm{H}_{60} \mathrm{O}_{4}[\mathrm{H}]$ has a DBE value of 3.5.

Once elemental assignment was completed, further visualization and data analysis were performed by using in-house tool KairosMS, ${ }^{48}$ in combination with custom $\mathrm{R}^{49}$ scripts; Upset plots were generated by using the Complex-Upset ${ }^{50}$ package.

\section{DISCUSSION}

Assessment of Base Oil Oxidation Observed in the BO Samples. Ultrahigh-resolution mass spectrometry data were acquired by both $(-)$ nESI and (+)APPI. The mass distribution for $(-)$ nESI data is dominated by oxygenated species; spectra are shown in Figure S2, with a similar appearance in profile from 0 to $168 \mathrm{~h}$. From an inspection of an enlarged section such as the $1 \mathrm{Da}$ section as shown on the left of Figure 1, however, the spectra can be shown to comprise

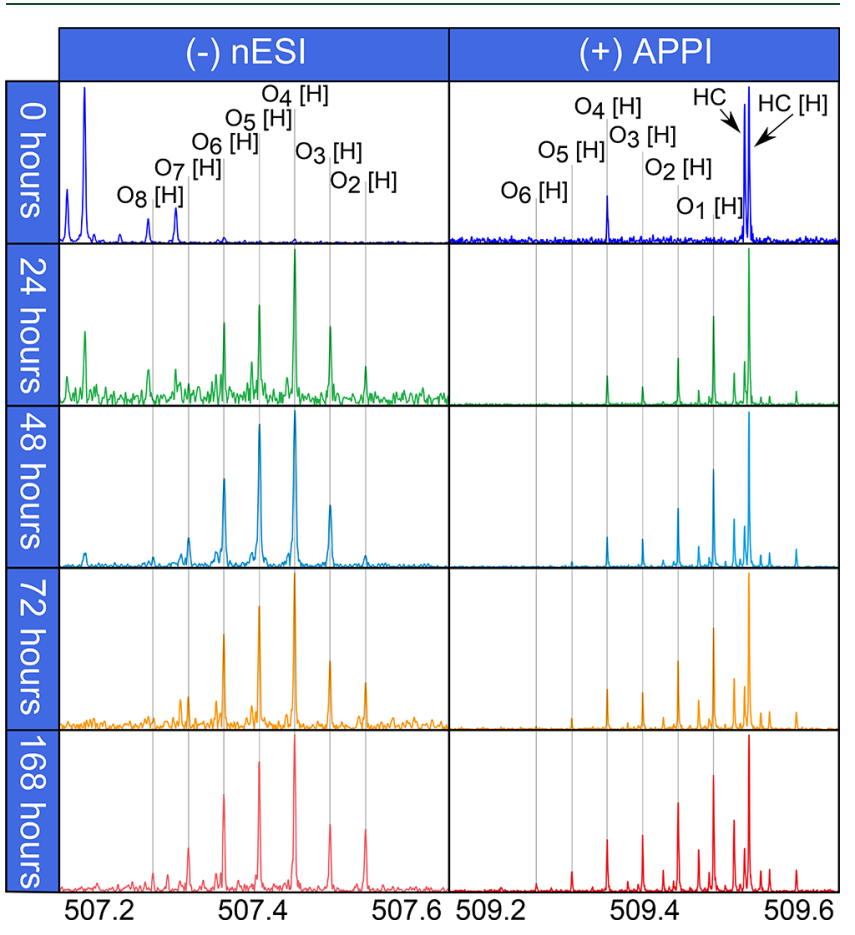

Figure 1. Enlarged section of the mass spectrum showing a series of oxygen containing species. Species with the same label in $(-)$ nESI and (+)APPI ionization modes most likely have both originated from (neutral) species with the same elemental formula. Broadband spectra for both $(-)$ nESI and (+)APPI can found in Figures S2 and S3.

homologous series of oxygenated species of the form $\mathrm{C}_{c} \mathrm{H}_{h} \mathrm{O}_{x}$, where $c$ is the carbon number, $h$ is the number of hydrogen atoms, and $x$ is the number of oxygen atoms. Typically, each Da contains a series of oxygenated species of the form $\mathrm{C}_{c} \mathrm{H}_{h} \mathrm{O}_{x}$ with a spacing of $36.4 \mathrm{mDa}$ equating to the $\mathrm{C}_{1} \mathrm{H}_{4}$ vs $\mathrm{O}_{1}$ mass split. The emergence of increasingly oxygenated classes can be observed from $24 \mathrm{~h}$ onward, greatly increasing the peak density of the spectra. Additionally, the relative intensity of more oxygenated species $\left(\mathrm{O}_{x}[\mathrm{H}]\right.$ where $\left.x \geq 3\right)$ species increase compared to $\mathrm{O}_{1}[\mathrm{H}]$ and $\mathrm{O}_{2}[\mathrm{H}]$ species, with increasing 


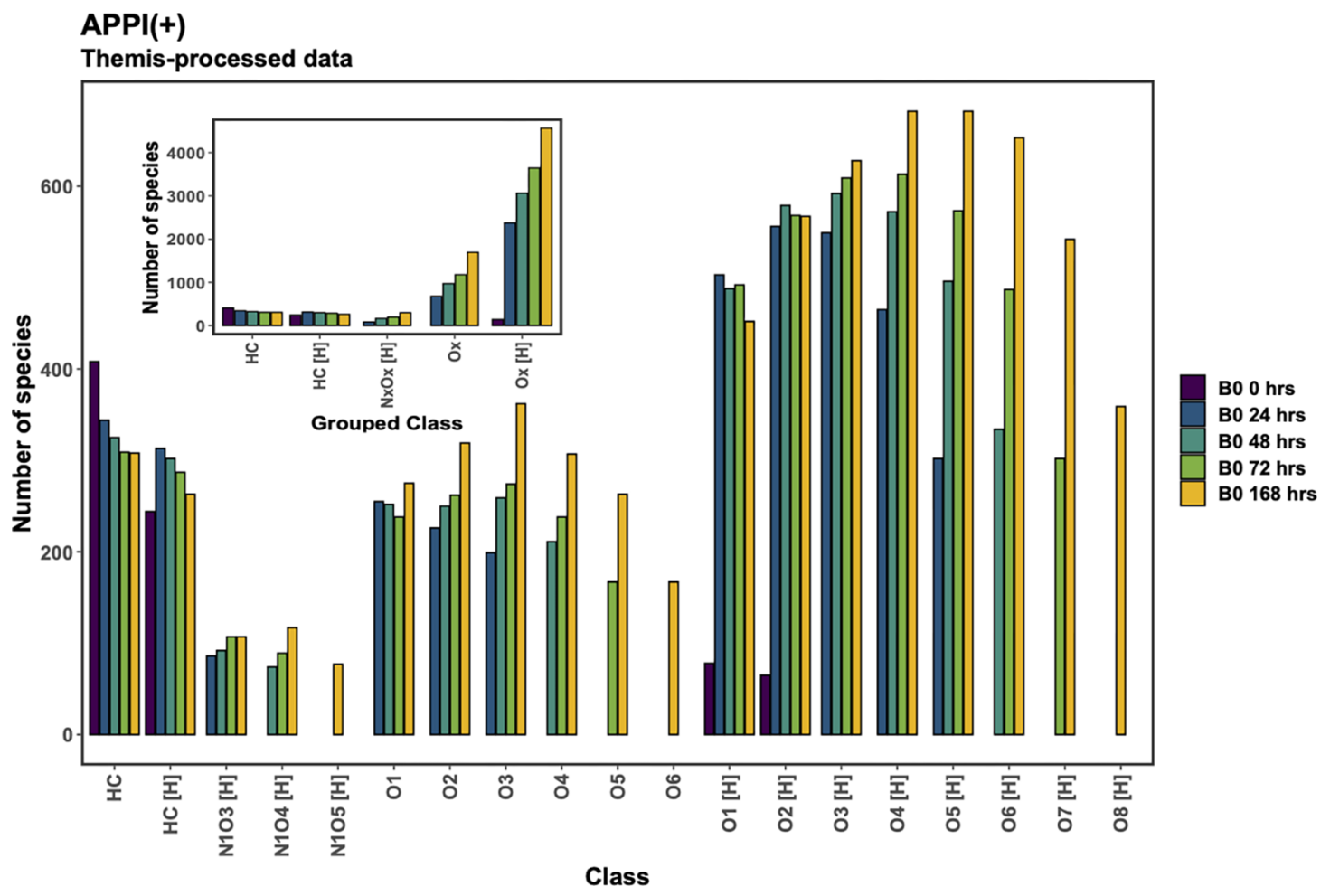

Figure 2. Class distribution of species obtained from B0 samples by positive-ion APPI. The number of species observed increases with oxidation time. Additionally, the dominant $\mathrm{O}_{x}$ class shifts to higher value of $x$ with increasing oxidation time.

oxidation time, indicating the increasing relative concentration of these species with the ongoing oxidation process.

The (+)APPI mass spectra, as shown in Figure S3, display the same characteristic "hump" profile as seen for petroleum distributions, with the distribution shifting toward higher mass with increasing oxidation time. Similarly, a zoomed $1 \mathrm{Da}$ inset of a (+)APPI spectrum, as shown on the right of Figure 1, shows the emergence of peaks assigned to oxygenated species. At $0 \mathrm{~h}$ typically only $\mathrm{HC}$ and $\mathrm{HC}[\mathrm{H}]$ species are observable; however, at $24 \mathrm{~h}$ onward multiple $\mathrm{O}_{x}$ species are observed. Similarly to the $(-)$ nESI spectra, typically a series of oxygenated species of the form $\mathrm{C}_{a} \mathrm{H}_{b} \mathrm{O}_{x}$ with a spacing of $36.4 \mathrm{mDa}$ are present; additionally, typically a pair of peaks corresponding to hydrocarbon species are observed: an oddelectron radical species and an even-electron protonated species with the mass split of ${ }^{13} \mathrm{C}_{1}$ vs ${ }^{12} \mathrm{C}_{1} \mathrm{H}_{1}(4.5 \mathrm{mDa})$. The typical even-electron species distribution per $\mathrm{Da}$ can then be assigned to a series of the form $\mathrm{C}_{c-x} \mathrm{H}_{h-4 x} \mathrm{O}_{x}[\mathrm{H}]$.

The number of monoisotopic species assigned per heteroatomic class can be summarized as a heteroatom class distribution as shown in Figure 2 for (+)APPI utilizing Themis-processed data. A corresponding class distribution for $(-) n E S I$ data can be found in the Supporting Information (see Figure S4). (-)nESI preferentially ionizes polar species such as carboxylic acids. Thus, the dominant classes observed in nESI spectra are $\mathrm{O}_{x}[\mathrm{H}]$ and $\mathrm{N}_{1} \mathrm{O}_{x}[\mathrm{H}]$ where $x$ ranges between 1 and 8; the number of $\mathrm{O}_{x}[\mathrm{H}]$ species increases with oxidation time as well as a shift toward higher values of $x$ for $\mathrm{O}_{x}$. In contrast, the (+)APPI mode enables access to less polar but more aromatic species, such as PAHs. APPI produces both even-electron and odd-electron radical species; however, evenelectron species typically dominate for heteroatom containing classes, whereas PAH species are typically observed as radical ions. ${ }^{51}$ The use of $(+)$ APPI has the advantage of ionizing hydrocarbon species that are present in the base oil and that are not ionized by $(-)$ nESI, enabling the tracking of the reactions that may increase or decrease the number of species present in the $\mathrm{HC}[\mathrm{H}]$ or $\mathrm{HC}$ classes.

The major classes observed in (+)APPI are $\mathrm{HC}, \mathrm{HC}[\mathrm{H}]$, $\mathrm{N}_{1} \mathrm{O}_{x}[\mathrm{H}], \mathrm{O}_{x}$, and $\mathrm{O}_{x}[\mathrm{H}]$. At $0 \mathrm{~h}$ (unoxidized) the sample comprises $\mathrm{HC}$ and $\mathrm{HC}[\mathrm{H}]$ species, with a small amount of $\mathrm{O}_{1}$ $[\mathrm{H}]$ and $\mathrm{O}_{2}[\mathrm{H}]$ species. Similarly, in $(-)$ nESI the number of species observed for $\mathrm{N}_{x} \mathrm{O}_{x}[\mathrm{H}], \mathrm{O}_{x}$ and $\mathrm{O}_{x}[\mathrm{H}]$ increase with oxidation time, and there is clear shift toward higher values of $x$ for $\mathrm{O}_{x}$ and $\mathrm{O}_{x}[\mathrm{H}]$ classes. A shift to higher $x$ values is due to increasing oxygen incorporation, from either the formation of polyoxidized species or the polycondensation of oxidized species. The number of $\mathrm{O}_{1}[\mathrm{H}]$ and $\mathrm{O}_{2}[\mathrm{H}]$ species do not show the same pattern. Instead, the number of $\mathrm{O}_{1}[\mathrm{H}]$ species decreases together with the number of species assigned to the $\mathrm{HC}[\mathrm{H}]$ class, suggesting these species are depleted either by further oxidation or by reactions to form more highly oxygenated products. The number of $\mathrm{O}_{2}[\mathrm{H}]$ species is more consistent, with minimal variation, suggesting that these species are regenerated by the ongoing oxidation of $\mathrm{O}_{1}[\mathrm{H}]$ or hydrocarbon species. For the $\mathrm{O}_{x}[\mathrm{H}]$ species where $x>2$, there is a clear trend of increasing number of species detected with time; as such, the diversity of each in terms of carbon number and DBE also increases, as shown in Figure S5. Similarly, an increase in the variety of oxidation products has been previously observed by FTIR measurements. ${ }^{52}$ Larger increases in the number of species present in a particular class between time points are observed for more oxygenated classes. For example, for the $\mathrm{O}_{4}[\mathrm{H}]$ class the number of species increases from $572 \rightarrow 613 \rightarrow 682$ when sampling from $48 \rightarrow$ $72 \rightarrow 168 \mathrm{~h}$; in the same time frame the $\mathrm{O}_{6}[\mathrm{H}]$ class increases from $334 \rightarrow 487 \rightarrow 653$ due to the additional reactive moieties afforded by $\mathrm{O}_{6}[\mathrm{H}]$ when compared to $\mathrm{O}_{4}[\mathrm{H}]$. 
The predominant class at each time point shifts from $\mathrm{HC}$ at zero hours (unoxidized) to $\mathrm{O}_{2}[\mathrm{H}]$ at $24 \mathrm{~h}, \mathrm{O}_{3}[\mathrm{H}]$ at $48 \mathrm{~h}$, and $\mathrm{O}_{4}[\mathrm{H}]$ at $72 \mathrm{~h}$. At $168 \mathrm{~h} \mathrm{O}_{4}[\mathrm{H}]$ and $\mathrm{O}_{5}[\mathrm{H}]$ are tied with equal number of species, suggesting a steady rate of oxidation for between 24,48 , and $72 \mathrm{~h}$, with the rate slowing by $168 \mathrm{~h}$. The decrease in the number of $\mathrm{HC}$ and $\mathrm{HC}[\mathrm{H}]$ species with increased oxidation time is expected due to depletion of hydrocarbon species by thermal oxidative degradation of the base oil. An initial increase in the number of $\mathrm{HC}[\mathrm{H}]$ species at $24 \mathrm{~h}$ was also observed, however, because of the formation of new hydrocarbon species. Formation of new aliphatic and aromatic species has been observed previously, ${ }^{24}$ and it is possible such species are formed from the alkylation of hydrocarbon species by an alkyl radical ${ }^{53}$ occurring during the initial stages of oxidation.

Some key metrics pertaining to $(-) \mathrm{nESI}$ and Themisprocessed (+)APPI data for B0 samples are given in Table 2; in

Table 2. Comparison of Metrics Obtained by (-)nESI and (+)APPI Mass Spectrometry

\begin{tabular}{|c|c|c|c|c|c|}
\hline sample & $\begin{array}{c}\text { no. } \\
\text { assigned } \\
\text { species }\end{array}$ & $\begin{array}{l}\text { no. assigned } \\
\text { monoisotopic }\end{array}$ & $\begin{array}{c}\text { carbon } \\
\text { no. } \\
\text { range }\end{array}$ & $\begin{array}{c}\text { mean } \\
\mathrm{O}_{x} \\
{[\mathrm{H}]} \\
\text { class }\end{array}$ & $\begin{array}{c}\text { mean } \mathrm{O}_{x}[\mathrm{H}] \\
\text { class (intensity } \\
\text { weighted) }\end{array}$ \\
\hline \multicolumn{6}{|c|}{$(-) \mathrm{nESI}$} \\
\hline B0 $0 \mathrm{~h}$ & 286 & 174 & $7-36$ & 4.1 & 2.5 \\
\hline B0 $24 \mathrm{~h}$ & 1547 & 1206 & $5-49$ & 4.1 & 2.5 \\
\hline B0 $48 \mathrm{~h}$ & 1575 & 1139 & $6-39$ & 4.3 & 3.9 \\
\hline B0 $72 \mathrm{~h}$ & 2578 & 1863 & $5-51$ & 4.4 & 2.9 \\
\hline B0 $168 \mathrm{~h}$ & 3589 & 2308 & $6-53$ & 4.9 & 3.4 \\
\hline \multicolumn{6}{|c|}{ (+)APPI } \\
\hline B0 $0 \mathrm{~h}$ & 1447 & 795 & $21-60$ & 1.5 & 1.4 \\
\hline B0 $24 \mathrm{~h}$ & 6804 & 3798 & $20-77$ & 2.8 & 1.9 \\
\hline B0 $48 \mathrm{~h}$ & 8935 & 4826 & $21-80$ & 3.3 & 2.2 \\
\hline B0 $72 \mathrm{~h}$ & 10075 & 5615 & $21-78$ & 3.8 & 2.5 \\
\hline B0 $168 \mathrm{~h}$ & 12499 & 7130 & $20-82$ & 4.4 & 2.9 \\
\hline
\end{tabular}

general, it can be seen (+)APPI enables the assignment of $\sim 3$ times the number of species compared to $(-)$ nESI and $\sim 3$ times the number of monoisotopic species. Species generated by $(-)$ nESI typically have a lower carbon number than that of
(+)APPI; additionally, the carbon number range covered by (+)APPI is greater. The mean $\mathrm{O}_{x}[\mathrm{H}]$ class is calculated by the mean number of oxygens present in monoisotopic evenelectron $[\mathrm{H}] \mathrm{O}_{x}$ classes; similarly, the intensity-weighted mean can be calculated by eq 1 , where the absolute intensity is the intensity of the $\mathrm{O}_{x}[\mathrm{H}]$ species and $O$ is the number of oxygen atoms present in the formula.

$$
\text { mean } \mathrm{O}_{x}[\mathrm{H}] \text { class }_{\text {intensity weighted }}=\frac{\sum \text { absolute intensity } \times O}{\sum \text { absolute intensity }}
$$

The mean $\mathrm{O}_{x}[\mathrm{H}]$ class metric can be used to indicate how oxidized the sample is relative to other samples; for (+)APPI this a clear trend of increasing $x$ value with oxidation time, as expected, reflecting the generation of species with increased oxygen content. For ( - nESI data, this metric only shows a minor trend of increasing $x$ value with time due to the dominance of $\mathrm{O}_{2}[\mathrm{H}]$ and $\mathrm{O}_{4}[\mathrm{H}]$ signals. These species are present from 0 to $168 \mathrm{~h}$ and likely carboxylic and dicarboxylic acids, respectively. Similarly, because of the dominance of $\mathrm{O}_{2}$ $[\mathrm{H}]$ and $\mathrm{O}_{4}[\mathrm{H}]$ signals, the intensity-weighted mean only shows a minor trend for $(-)$ nESI data. The outlier value for B0 $48 \mathrm{~h}$ is mostly due to the high intensity of two $\mathrm{O}_{4}[\mathrm{H}]$ species: $\mathrm{C}_{32} \mathrm{H}_{64} \mathrm{O}_{4}[\mathrm{H}](\mathrm{m} / z 511.4732)$ and $\mathrm{C}_{34} \mathrm{H}_{68} \mathrm{O}_{4}[\mathrm{H}]$ $(\mathrm{m} / z$ 539.5039). For (+)APPI data the intensity-weighted metric shows a clear increase in the value of $x$ with oxidation time. Although both the mean $\mathrm{O}_{x}[\mathrm{H}]$ value and the intensityweighted value show similar trends, the actual values are quite different, especially at higher oxidation times. Highly oxygenated species are typically observed at a relative lower intensity than less oxygenated species, which is shown by the lower value of the intensity weighted metric compared to the simple mean. Based upon these metrics, (+)APPI offers superior performance for the ionization of unoxidized and oxidized base oil species due to the enhanced carbon number range, 3-fold increase in assignments, and easier determination of $\mathrm{O}_{x}[\mathrm{H}]$ class by both simple mean and intensity-weighted approaches. Because of the benefits afforded by (+)APPI, the following analyses will be performed with $(+)$ APPI only.

Changes in Carbon Number and Double Bond Equivalents. Oxidation of base oils is known to form high

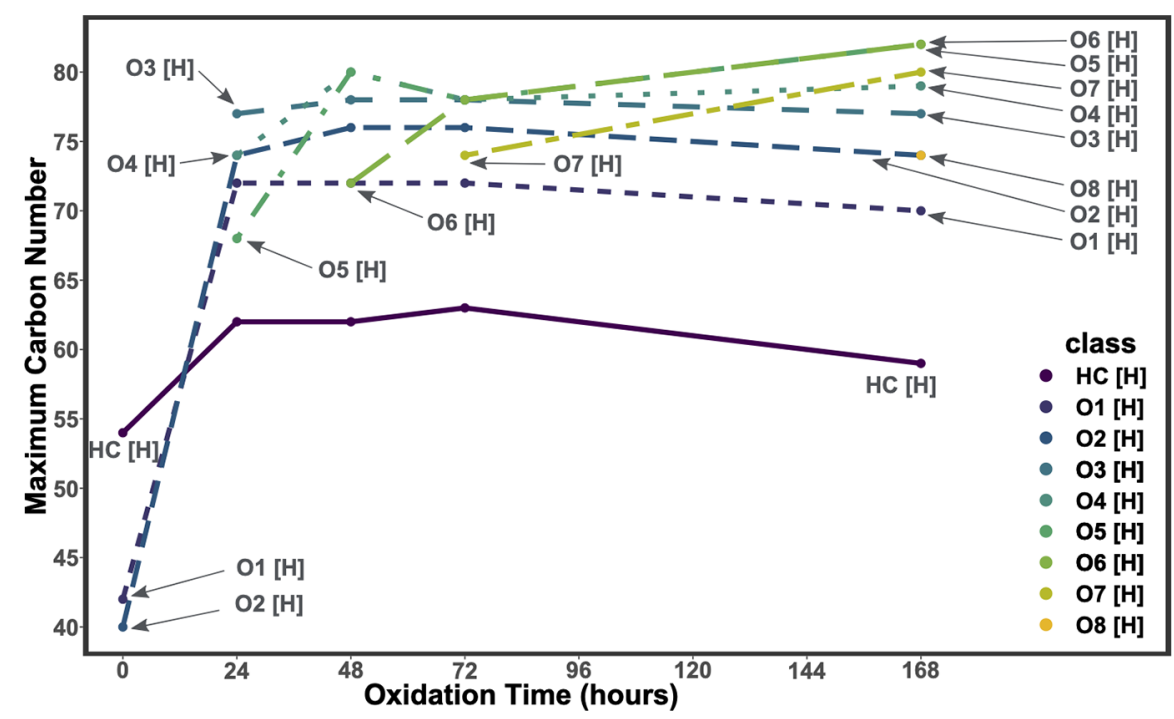

Figure 3. Maximum carbon number observed for $\mathrm{HC}[\mathrm{H}]$ and $\mathrm{O}_{1}[\mathrm{H}]-\mathrm{O}_{8}[\mathrm{H}]$ species by $(+)$ APPI. 


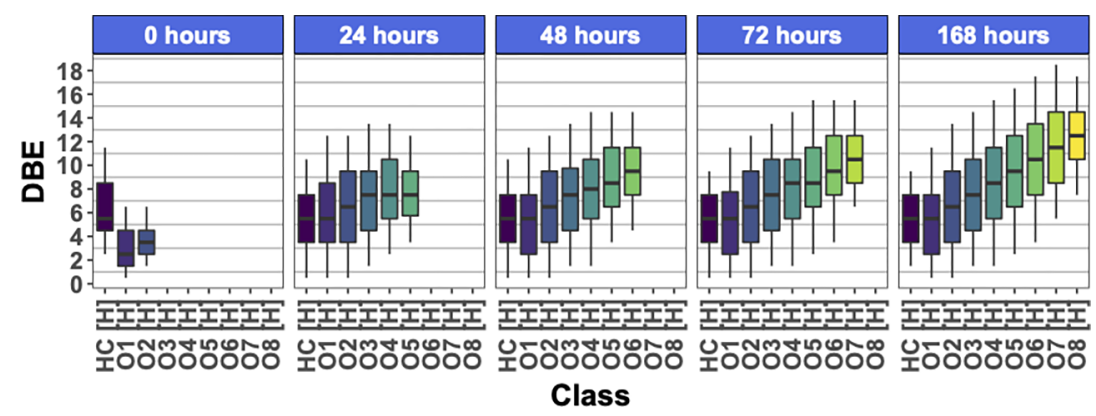

Figure 4. Boxplots of the DBE ranges for $\mathrm{HC}[\mathrm{H}]$ and $\mathrm{O}_{x}[\mathrm{H}]$ species present in Themis-processed $\mathrm{B} 0$ data sets.

molecular weight material from progressive polycondensation which eventually leads to sludge and varnish formation. ${ }^{5}$ In addition, the successive alkylation of aromatic rings through the free-radical mechanism ${ }^{53}$ leads to increases in the total number of carbon atoms in the molecule. We can observe the effect of processes that increase the carbon number of the molecule via mass spectrometry by investigating the changes in the carbon number ranges observed; however, it is not possible to determine whether species have a linear or branched structure with direct infusion mass spectrometry alone. Additional techniques such as gas chromatography $(\mathrm{GC})^{24,26,28}$ or two-dimensional mass spectrometry ${ }^{54}$ would have to be employed to provide further insight into the structural arrangement of the carbon skeleton.

The maximum carbon number observed for a selection of protonated classes by $(+) A P P I ; H C[H]$, and $\mathrm{O}_{1}[\mathrm{H}]$ to $\mathrm{O}_{8}$ $[\mathrm{H}]$ with increasing oxygen incorporation is plotted in Figure 3. After processing the replicates by using Themis, we used the data to construct a single plot to simplify analysis. Additional plots for each replicate can be found in the Supporting Information (Figures S6 and S7). In the $\mathrm{HC}[\mathrm{H}]$ class an increase in carbon number of 8 between 0 and $24 \mathrm{~h}$ is observed, which is further evidence for alkylation reactions. Afterward, the maximum carbon number remains approximately stable with an increase of only 1 between 24 and $72 \mathrm{~h}$, which suggests the hydrocarbons present are resistant to alkylation reactions. Beyond $72 \mathrm{~h}$, the maximum carbon number for $\mathrm{HC}[\mathrm{H}]$ decreases by 4 , and as such, high carbon number $\mathrm{HC}[\mathrm{H}]$ species are not observed at $168 \mathrm{~h}$ because of hydrocarbon degradation. The $\mathrm{O}_{1}[\mathrm{H}]$ and $\mathrm{O}_{2}[\mathrm{H}]$ classes can provide useful information about which species in the base oil may be readily oxidized, as these classes will comprise species generated in the early stages of oxidation such as alcohols, aldehydes, and ketone species in the case of $\mathrm{O}_{1}[\mathrm{H}]$ and carboxylic acids or difunctionalities (diols, dicarbonyl, or similar) in the case of $\mathrm{O}_{2}[\mathrm{H}]$. Protection of the precursors of these $\mathrm{O}_{1}[\mathrm{H}]$ and $\mathrm{O}_{2}[\mathrm{H}]$ species may be ideal targets for the development of antioxidant chemistries.

The large increase in carbon number from 0 to $24 \mathrm{~h}, 30$ for $\mathrm{O}_{1}[\mathrm{H}]$, and 34 for $\mathrm{O}_{2}[\mathrm{H}]$ greatly exceeds the maximum carbon number observed for $\mathrm{HC}[\mathrm{H}]$. One possible explanation of the origin of the $\mathrm{O}_{1}[\mathrm{H}]$ and $\mathrm{O}_{2}[\mathrm{H}]$ species observed at $24 \mathrm{~h}$ is that they are oxidized products of long chain hydrocarbon species that are not accessible by APPI, such as paraffinic species, due to the greatly increased maximum carbon number relative to $\mathrm{HC}[\mathrm{H}]$. Alternatively, the species at $24 \mathrm{~h}$ are generated from radical reactions in the chain propagation and chain branching steps of oxidation that increase the alkyl chain length or, in the case of $\mathrm{O}_{2}[\mathrm{H}]$, aldol condensation reactions. ${ }^{5}$ Beyond $24 \mathrm{~h}$, the maximum carbon number observed for $\mathrm{O}_{1}[\mathrm{H}]$ and $\mathrm{O}_{2}[\mathrm{H}]$ does not vary considerably. The classes $\mathrm{O}_{3}[\mathrm{H}]$ and $\mathrm{O}_{4}[\mathrm{H}]$ display minimal variation in maximal carbon number, suggesting that these species are not typical products of polycondensation reaction, as increases in carbon number would be expected if that was the case. Highly oxygenated classes such as $\mathrm{O}_{5}[\mathrm{H}]$ and above display a clear trend of increasing carbon number with oxidation time, suggesting that these species could be the products of successive polycondensation reactions. Additive developments that then limit these successive polycondensation reactions may then limit the formation of high oxygenated material.

The number of rings and double bond equivalents (DBE) can be used to infer the aromaticity of species or the degree of unsaturation. A boxplot of the double bond equivalents of the protonated classes, $\mathrm{HC}[\mathrm{H}]$, and $\mathrm{O}_{1}[\mathrm{H}]$ to $\mathrm{O}_{8}[\mathrm{H}]$ is shown in Figure 4 where a trend of increasing mean DBE with both oxygen content and oxidation time is observed. At $0 \mathrm{~h}, \mathrm{HC}$ $[\mathrm{H}]$ species have a relatively high mean $\mathrm{DBE}$ of 6 , suggesting that these species likely contain either a single aromatic ring or have unsaturated ring structures, or combinations of both. The $\mathrm{O}_{1}[\mathrm{H}]$ and $\mathrm{O}_{2}[\mathrm{H}]$ species observed have a lower mean DBE relative to $\mathrm{HC}[\mathrm{H}]$ of approximately 3 and 3.6, respectively, and as such are likely single or dicarbonyl (in the case of $\mathrm{O}_{2}$ $[\mathrm{H}]$ ) species, or aromatic alcohol species, as aliphatic alcohol species are not readily ionizable by APPI. ${ }^{51}$ From 24 to $168 \mathrm{~h}$ the mean $\mathrm{DBE}$ for $\mathrm{HC}[\mathrm{H}]$ species remains constant at 5.5, indicating minimal changes to the degree of saturation or number of rings present. The $\mathrm{O}_{x}[\mathrm{H}]$ classes show a clear trend of increasing DBE when going from $\mathrm{O}_{x}[\mathrm{H}]$ to $\mathrm{O}_{x+1}[\mathrm{H}]$, which suggests each successively more oxygenated class contains an additional double bond such as the formation of a carbonyl. There also seems to be a trend of increasing mean $\mathrm{DBE}$ of a class with increasing oxidation time, such as $\mathrm{O}_{5}[\mathrm{H}]$, which shows a steady increase from 24 to $168 \mathrm{~h}(7.8 \rightarrow 8.8 \rightarrow$ $9.0 \rightarrow 9.3)$ due to the formation of higher DBE material; this can be visualized by a plot of number of species for each DBE shown in Figure S8. Formation of increased DBE species of the same class suggests that more condensed species (with higher number of rings and double bonds) such as saturated ring structures ${ }^{53}$ are formed and that more of the oxygen atoms are present in carbonyl moieties.

Further assessment of the mean DBE per $\mathrm{O}_{x}[\mathrm{H}]$ class can suggest which oxygen-containing moieties are present. For example, formation of a carbonyl group would increase the DBE by one, while formation of a hydroxyl group does not increase the DBE. A linear model for the mean DBE of each class at each time point, in the form mean $\mathrm{DBE}=$ grad $\times O+b$, where $O$ is the oxygen content, grad is the gradient of the line, and $b$ is the intercept, can be used to assess 
the oxygen functionality present. To ensure the accurate determination of the mean DBE only species with an assigned ${ }^{13} \mathrm{C}$ isotopologue were included in the calculation, both replicate and Themis-processed data were included. The equation of each line can be found in Table 3, and a plot of

\section{Table 3. Terms of Linear Model}

$\begin{array}{cccc}\begin{array}{c}\text { time point } \\ (\mathrm{h})\end{array} & \begin{array}{c}\text { equation of line: } \\ \text { mean DBE }=\text { grad } \times O+b\end{array} & \begin{array}{c}1 / \\ \text { grad }\end{array} & R^{2} \\ 24 & \text { mean DBE }=0.63 O+4.63 & 1.58 & 0.991 \\ 48 & \text { mean DBE }=0.83 O+4.39 & 1.20 & 0.995 \\ 72 & \text { mean DBE }=0.93 O+4.15 & 1.07 & 0.996 \\ 168 & \text { mean DBE }=1.05 O+3.81 & 0.95 & 0.996\end{array}$

the fitted line can be found in Figure S9. At 0 h only $\mathrm{O}_{1}$ and $\mathrm{O}_{2}$ species are present. As such, it is not possible to accurately model the DBE change with increasing content $\left(R^{2}\right.$ value of only 0.804$)$; however, $24-168 \mathrm{~h}$ enabled the fitting of the linear model (all $R^{2}$ values $>0.99$ ).

An increase in one DBE for an increase of two oxygen atoms would suggest the presence of an additional carboxylic acid group or ester, whereas an increase in one DBE per oxygen atoms suggests the formation of carbonyl species. The number of oxygen atoms required for an increase of one DBE decreases with oxidation time (from 1.58 to 0.95 ), as such with increasing oxidation time more oxygen content is likely to arise from the formation of carbonyl groups. The formation of additional condensed structures would also reduce the number of oxygen atoms required (as obtained by the linear model); nevertheless, increasingly oxygenated species have a greater chemical diversity due to the possible combinations of different oxygen-containing moieties. Therefore, highly oxygenated species would be expected to form more condensation products than less highly oxygenated species.

The significant changes in the $\mathrm{HC}, \mathrm{HC}[\mathrm{H}], \mathrm{O}_{1}[\mathrm{H}]$, and $\mathrm{O}_{2}$ $[\mathrm{H}]$ classes between 0 and $24 \mathrm{~h}$ were further investigated as this time range covers the initial stages of oxidation. The species in common and those that are unique between 0 and $24 \mathrm{~h}$ are plotted as a DBE versus carbon number plot shown in Figure 5. The species in blue are those that are unique to the 0 $\mathrm{h}$ samples; thus, they are no longer observed at $24 \mathrm{~h}$, likely due to oxidative degradation. Species colored in green are those that are common between samples; as such, these species can be considered to remain in the sample after oxidation due to either high concentration or oxidative stability. Species colored in gray are species unique to the $24 \mathrm{~h}$ sample; therefore, they are species that have been generated from the oxidation of the 0 h sample. The high DBE species of HC (odd-electron) class are lost after oxidation; these are most likely structures with multiple aromatic cores. Multiring aromatics have been suggested to have an antioxidant effect due to formation of phenols; ${ }^{7}$ however, as their concentration in Group II base oils is low, they are not expected to have a significant effect on the oxidation. ${ }^{55,56}$ In comparison, only a small number of species are lost from the $\mathrm{HC}[\mathrm{H}]$ class, highlighting that $\mathrm{HC}$ and $\mathrm{HC}$ $[\mathrm{H}]$ classes represent chemically different species. A significant number of new $\mathrm{HC}[\mathrm{H}]$ species are observed at an increased carbon number, likely generated by the reaction of alkyl radicals with hydrocarbon species. Several low DBE species of class $\mathrm{HC}[\mathrm{H}]$ are also generated; these may be single ring species such as naphthenic species, generated either as breakdown products or from the cyclization of paraffinic

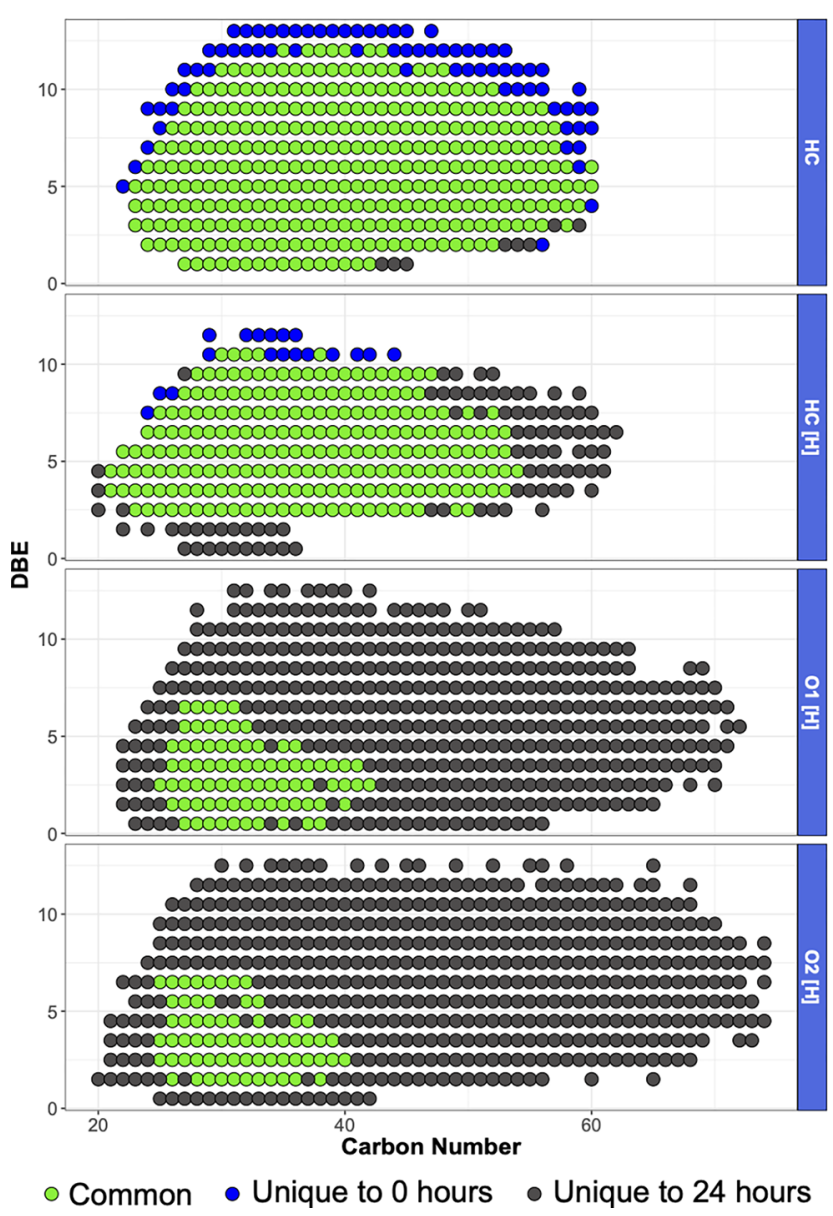

Figure 5. DBE versus carbon number plots displaying the species observed at 0 and $24 \mathrm{~h}$. Species in green are observed at both 0 and 24 $\mathrm{h}$, species in blue are only observed at $0 \mathrm{~h}$, and species in gray are only observed at $24 \mathrm{~h}$.

species. Both the $\mathrm{O}_{1}[\mathrm{H}]$ and $\mathrm{O}_{2}[\mathrm{H}]$ class display a larger increase in the number of species, with a broader range of carbon numbers and DBE observed. The DBE range observed at $24 \mathrm{~h}$ is similar to that of $\mathrm{HC}$ and $\mathrm{HC}[\mathrm{H}]$ species at $0 \mathrm{~h}$, providing evidence that some of the species are the direct oxidized products of $\mathrm{HC}$ and $\mathrm{HC}[\mathrm{H}]$ species. The carbon range is significantly higher in the $\mathrm{O}_{1}[\mathrm{H}]$ and $\mathrm{O}_{2}[\mathrm{H}]$ classes, however, indicating the likelihood of oligomerization reactions.

Effect of Biodiesel Addition. The oxidation of both base oil and biodiesel components produces increasingly complex mixtures due to the additional reactive pathways introduced by the biodiesel. As such, analysis of the biodiesel-doped base oil samples can prove more challenging than oxidized base oil alone.

Conventional Analysis (Kinematic Viscosity and FTIR). The plot of oxidation rating (an FTIR measurement of the carbonyl absorbance made according to the standard method DIN 51453) versus increasing oxidation time is given in Figure S10A. Kinematic viscosity at $100{ }^{\circ} \mathrm{C}$ ( KV 100) versus oxidation time plots are given in Figure S10B. Tabulated data are provided in Table S5. As expected, both the kinematic viscosity and oxidation rating increase with oxidation time, with minimal variation between B0, B15, and B100 samples, except for the recorded kinematic viscosity of the B15 sample at $168 \mathrm{~h}$, which is much lower than that recorded for either B0 or B100. The is likely due to the increased polarity of the B15 

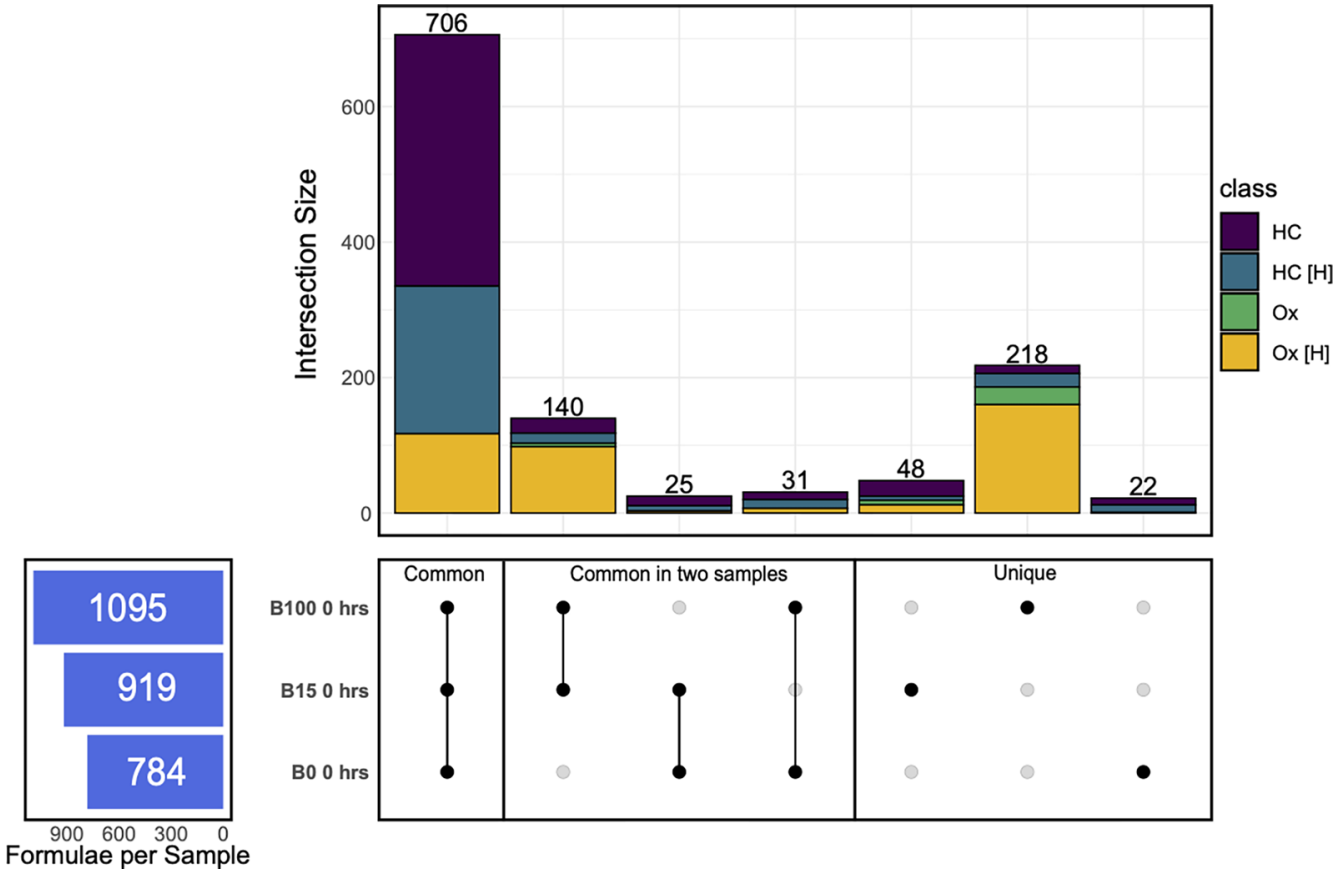

Figure 6. An Upset plot of $0 \mathrm{~h}$ sample composition for B0, B15, and B100.

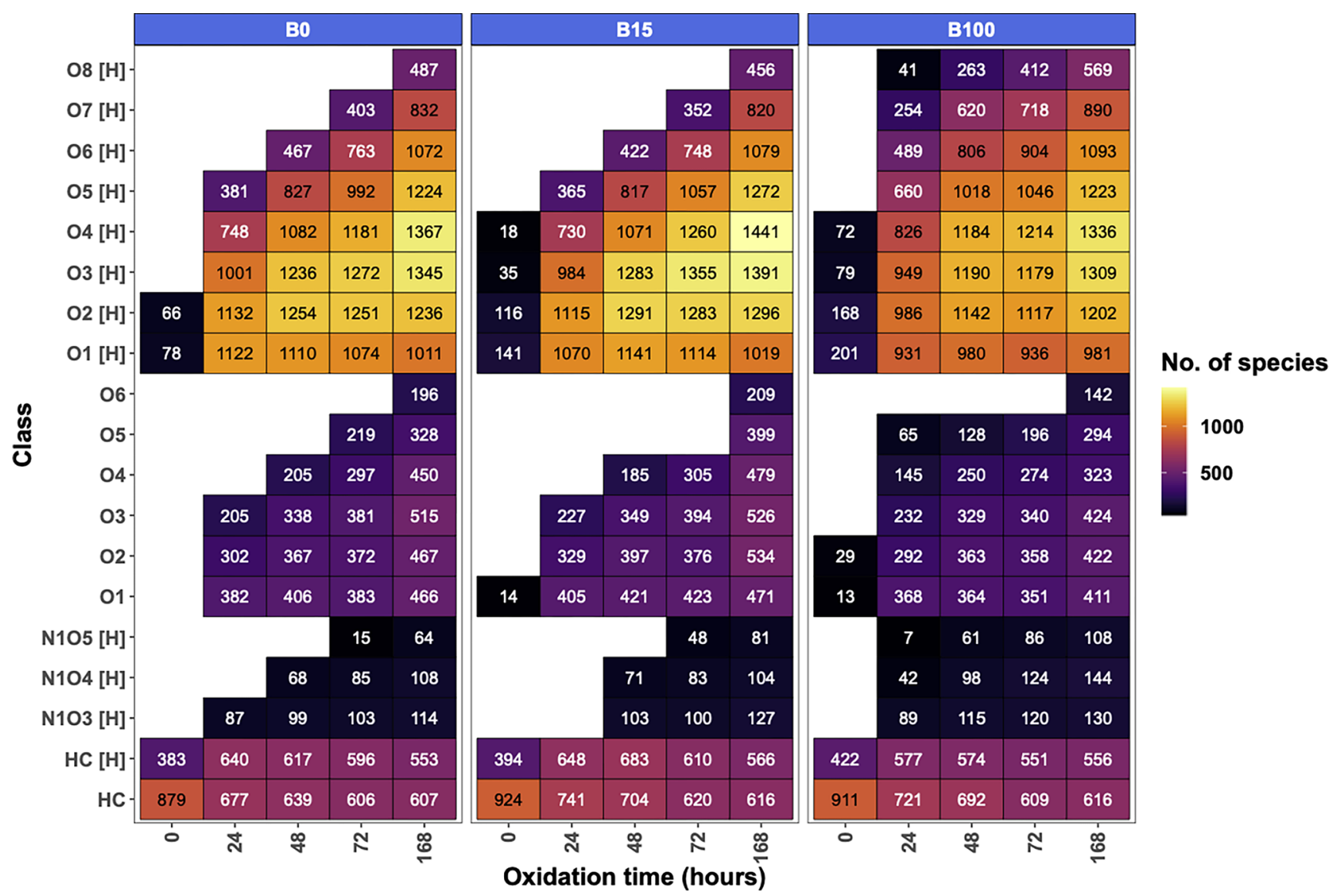

Figure 7. Class distribution for assigned monoisotopic species for B0, B15, and B100 samples

sample compared to B0, which improves the dispersion of oxidized material, thereby lowering the viscosity. In the case of $\mathrm{B} 100$ versus $\mathrm{B} 15$, an increased amount of polycondensation is expected in the B100 sample due to the increased biodiesel content, which leads to generation of higher viscosity material.
This is likely to have a more significant effect than the increased solvency from going from B15 to B100; hence, the measured viscosity increases for B15 relative B100. Similar solubility phenomena have been observed with measurements of deposit weight. ${ }^{57}$ The $\mathrm{pH}$ values for the $168 \mathrm{~h}$ samples for 
each biodiesel level were also recorded at $\mathrm{pH} 1.6,1.8$, and 1.5 for $\mathrm{B} 0, \mathrm{~B} 15$, and $\mathrm{B} 100$, respectively. This indicates that the most acidic sample at $168 \mathrm{~h}$ was B100 followed by B0, with the least acidic being B15.

FTICR MS Analysis. The mass spectra profiles for B0, B15, and B100 by (+)APPI all share the same broad "petroleum" style distribution, and as such, it is not possible to easily identify biodiesel from the mass spectra profile alone. It is possible, however, to identify species that are present in the B15 and B100 samples that are not present in the B0 sample, as shown by Figure S13. To gauge the increased chemical diversity due to the biodiesel, an Upset plot ${ }^{58}$ was constructed from the $0 \mathrm{~h}$ time points of B0, B15, and B100, as shown in Figure 6. For the following analyses to ensure parity between $\mathrm{B} 0$ and B15/B100 sample sets a single replicate $(r 2)$ was selected to represent B0 samples.

The Upset plot in Figure 6 displays the species in common and those which are unique for the $0 \mathrm{~h}$ samples for B0, B15, and B100. Each row in the matrix represents a sample (B0, $\mathrm{B} 15$, or $\mathrm{B} 100)$, each column is an intersection, and the samples present in each intersection are signified by a filled black dot in their respective row; if multiple samples are present in an intersection, the black dots are connected by a solid black line. In similarity to a Venn diagram, the intersection size represents the number of species that are present in that intersection; additionally, the intersection size is then split into constituent heteroatom classes.

As shown in the Figure 6, 706 species, composed of hydrocarbon and oxygenated species, are common between all $0 \mathrm{~h}$ samples. These species are common between all $0 \mathrm{~h}$ samples as they originate from the base oil itself. An additional 140 species were found in common between the B15 and B100 samples, and most of these species are oxygenated species $\left(\mathrm{O}_{1}-\mathrm{O}_{4}\right)$; as such, these can likely be attributed to the fatty acid methyl ester (FAME) biodiesel present in the sample. A significant number of species are unique to the B100 sample (218), most being oxygenated $\left(\mathrm{O}_{1}-\mathrm{O}_{4}\right)$, and are likely species also present in the biodiesel mixture that were not detected in the B15 sample due to the decreased biodiesel concentration. Few (25) species were found to be common between B0 and $\mathrm{B} 15$ and are likely due to the petroleum diesel. In addition, 48 unique species were found in B15, mostly of hydrocarbon and oxygenated classes; these either represent species present in the diesel mixture or possibly products formed from mixing the biodiesel with the petroleum diesel. A small number of species (31) were also found in common between B0 and B100; these are most likely species that are present but were not detected in the B15 sample. The sample complexity increases from 784 species for the B0 sample to 919 for the B15 sample and 1095 for the B100 sample; it is clear that the addition of biodiesel increases the complexity of the sample.

The class distribution for assigned monoisotopic species for each level of biodiesel is given in Figure 7. The same trend of increasing number of $\mathrm{O}_{x}$ species and a shift to higher values of $x$ for $\mathrm{O}_{x}$ with increasing oxidation time, as previously observed for B0 samples, are seen for both B15 and B100. B15 behaves very similarly to $\mathrm{B} 0$ with a similar number of species generated at each time point; as such, the additional biodiesel species at this level of doping appear to a have a limited effect on increasing the generation of oxidized products. B100, however, displays a significant increase relative to $\mathrm{B} 0$ and $\mathrm{B} 15$ in the number of oxygenated species present at 24,48 , and $72 \mathrm{~h}$. Additionally, $\mathrm{O}_{6}[\mathrm{H}]$ to $\mathrm{O}_{8}[\mathrm{H}]$ species are observed at reduced oxidation times when compared to both $\mathrm{B} 0$ and $\mathrm{B} 15$. The classes $\mathrm{O}_{6}[\mathrm{H}], \mathrm{O}_{7}[\mathrm{H}]$, and $\mathrm{O}_{8}[\mathrm{H}]$ are first observed at 48,72 , and 168 h, respectively, for both $\mathrm{B} 0$ and $\mathrm{B} 15$, whereas these three classes are first observed for B100 at $24 \mathrm{~h}$, suggesting that B100 significantly increases the rate of oxidation and generation of polyoxygenated species. Previous studies ${ }^{18}$ have found an increase in ester formation of biodiesel containing fuel blends with oxidation time due to the reaction of alcohols and carboxylic acids formed from FAMEs oxidation. Thus, some of the additional oxidized species observed for B15 and B100 samples are likely ester-containing species. At the $168 \mathrm{~h}$ time point all samples (B0, B15, and B100) have a very similar distribution of species across the heteroatom classes.

The ongoing oxidation of the base oil is expected to increase the chemical diversity in terms of the number of unique species generated. As such, the oxidation of the different biodiesel blends can be summarized and compared by the total number of monoisotopic species observed as shown in Figure 8A. At 0
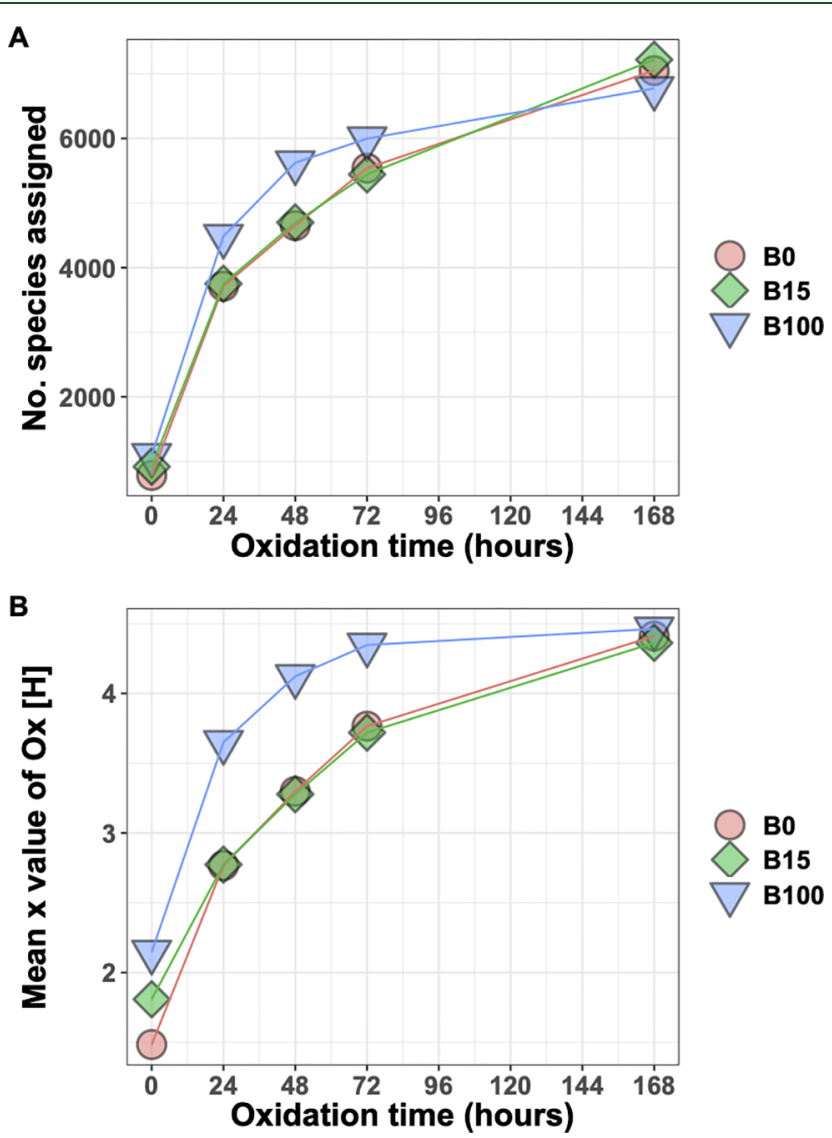

Figure 8. (A) Plot of number of monoisotopic species assigned in each sample by (+)APPI FTICR MS. (B) Plot of mean $x$ value of $\mathrm{O}_{x}$ $[\mathrm{H}]$ species.

$\mathrm{h}$ the B100 sample is the most complex in terms of assigned species, followed by B15 and then B0 due to additional species present in the biodiesel. At 24, 48, and $72 \mathrm{~h}, \mathrm{~B} 100$ is significantly more complex than either $\mathrm{B} 15$ or $\mathrm{B} 0$ due to the generation of additional oxidized material. B15 and B0 show a similar level of complexity, however; therefore, B15 does not cause a significant increase in complexity relative to B0. This observation is consistent with previous research which suggests low loading of biodiesel (B30 and below $)^{20}$ does not display as 
significant oxidation as B100. At $168 \mathrm{~h}$ all samples are clustered together with similar numbers of assignments; this suggests that at $168 \mathrm{~h}$ a similar level of oxidation has occurred. It is important to note that although B100 has the lowest number of assigned species at $168 \mathrm{~h}$, it still has a higher kinematic viscosity compared to $\mathrm{B} 15$ and $\mathrm{B} 0$. It is possible that specific species present in the B100 sample may significantly influence kinematic viscosity. An analysis of the species unique to each $168 \mathrm{~h}$ sample, as shown in Figure S11, indicates that the B100 sample contains highly oxygenated species, in particular $\mathrm{O}_{8}$ $[\mathrm{H}]$, that are not present in either B15 or B0 samples. A DBE plot (Figure S12) of these unique species suggests that B100 $168 \mathrm{~h}$ unique species are highly oxygenated with a typically lower DBE than B0 or B15 unique species; these species are possibly polycarboxylic acids. However, further investigation is needed to confirm this.

The oxygen content of the species can be summarized by the mean oxygenated class (mean $x$ value of $\mathrm{O}_{x}[\mathrm{H}]$ ) as plotted in Figure 8B. A general trend of increasing value of $x$ for $\mathrm{O}_{x}[\mathrm{H}]$ is observed due to the generation of increasingly more oxygenated species. As expected at $0 \mathrm{~h}, \mathrm{~B} 100$ has a higher mean value of $\mathrm{O}_{x}[\mathrm{H}]$ of 2.1 followed by B15 (1.8) and $\mathrm{B} 0$ (1.5) due to presence of additional polyoxygenated species in the biodiesel $\left(\mathrm{O}_{3}[\mathrm{H}]\right.$ and $\left.\mathrm{O}_{4}[\mathrm{H}]\right)$ species. Between 24 and 72 $\mathrm{h}$, the mean $x$ value of $\mathrm{B} 100$ is significantly higher than that of $\mathrm{B} 15$ and B0 due to the generation of polyoxygenated species, $\mathrm{O}_{x}[\mathrm{H}]$ species where $x \geq 5$. B0 and B15 have very similar values, as such $\mathrm{B} 15$ does not seem to cause the generation of significantly more oxygenated species than B0 alone. This is likely due to the low loading of biodiesel (15\%) and high percentage of petroleum diesel $(85 \%)$ in the B15 sample, making the B15 sample more similar to the B0 sample in terms of chemical composition; it would therefore be expected to have a similar behavior to the B0 sample. It is however possible that additional species were generated in the oxidized B15 sample but were subsequently lost due to their volatile nature.

At $168 \mathrm{~h}$, the mean $x$ value of $\mathrm{O}_{x}[\mathrm{H}]$ converges to $\sim 4.4$, similar to the convergence of the number of species assigned at this time point. Considering both the number of species observed and mean $\mathrm{O}_{x}[\mathrm{H}]$ class, the addition of biodiesel can be considered to accelerate the oxidation of the base oil, as seen by the elevated number of species and value of $\mathrm{O}_{x}[\mathrm{H}]$ between 24 and $72 \mathrm{~h}$. All samples have a similar number of species present at $168 \mathrm{~h}$, however, which suggests that all easily oxidizable material has been oxidized within the sample after $168 \mathrm{~h}$.

When using an isolation window in conjunction with an increased low-mass cutoff, as compared to broadband spectra, an increased resolving power results. To further probe the similarity of samples of differing biodiesel contents at $168 \mathrm{~h}$, an isolation window with an $m / z$ width of 40 and centered at $m / z$ 700 was used for each of the B0, B15, and B100 samples. No significant differences were observed, however (see Figure S14). It is possible B100 does display some additional complexity that is not observed due to ionization competition, which may be determined and resolved by either offline sample fractionation prior to direct infusion analysis or by using online chromatography coupled to FTICR-MS such as GC- ${ }^{59}$ or liquid chromatography (LC)-FTICR-MS. ${ }^{60}$

Assessment of FTICR MS for Oxidized Base Oil Analysis. Previous studies have shown FTICR MS is well suited to base oil analysis, ${ }^{22,28}$ with the use of $(+)$ APPI or $(+)$ APCI preferred as these techniques are both able to ionize the hydrocarbon base material. In this study, (+)APPI and $(-)$ nESI methods were compared, and ionization of hydrocarbon components was found to be desirable in order track oxidation pathways. The oxidized material is both efficiently ionized by (+)APPI and (-)nESI and was found to contain species containing multiple oxygen atoms.

\section{CONCLUSIONS}

FTICR-MS has proved well suited to the analysis of the complex samples produced from oxidation of a Group II base oil via a benchtop oxidation method.

- Both (-)nESI and (+)APPI were efficient at ionizing oxygen-containing base oil oxidation products, with (+)APPI preferred due to the access to hydrocarbon species.

- Base oil oxidation was found to produce polyoxygenated species containing $1-8$ oxygen atoms, with the generation of increasingly oxygenated compounds favored with increasing oxidation time.

- Assessment of the mean DBE for $\mathrm{O}_{x}[\mathrm{H}]$ containing classes indicated that the carbonyl content of each $\mathrm{O}_{x}$ $[\mathrm{H}]$ class increased with oxidation time; additionally, assessment of the maximum carbon number of each class provided evidence of oligomerization reactions.

- The oxidation of B0, B15, and B100 containing samples was compared between 0 and $168 \mathrm{~h}$. At 24, 48, and $72 \mathrm{~h}$ time points, the B100 sample displayed an increased number of polyoxygenated species, indicating faster oxidation, compared to B0 and B15 samples.

- At $168 \mathrm{~h}$ all samples displayed a similar number of oxygenated species, providing evidence that all easily oxidized material has been oxidized by $168 \mathrm{~h}$.

- The B15 samples did not contain significantly more oxidized species as compared to B0; thus, $15 \%$ biodiesel concentration did not significantly degrade the oxidative stability of the base oil.

This study provides a method for characterizing Group II base oil oxidation by FTICR MS; the detailed characterization affords further understanding of fundamental oxidation processes occurring in base oil samples. The findings may be potentially used for development of additional additives either to target material that is easily oxidizable and then therefore delay the onset of oxidation or to prevent the formation of highly oxygenated polymeric material which may be prone to deposit formation. This method can also be applied to other base oil groups such as Groups III/IV; the same methodology should also be applicable to other hydrocarbon-based oil groups. Alternative chemistries such as those found in Group V oils may require alternative optimal ionization methods. This method is also applicable to fully formulated engine oils; however, (+)APPI ionization may be preferred to avoid signal suppression occurring due to preferential ionization of additive components occurring in ESI. This method may be further expanded with the use of online chromatography methods such as GC-FTICR-MS to resolve isomeric species and verify the functionality and structure of oxidation products.

\section{ASSOCIATED CONTENT}

\section{SI Supporting Information}

The Supporting Information is available free of charge at https://pubs.acs.org/doi/10.1021/acs.energyfuels.1c01240. 
Base oil properties (Table S1); oxidation test setup (Figure S1); calibration lists (Tables S2-S4); broadband mass spectra (Figures S2 and S3); nESI class distribution (Figure S4); additional carbon number and DBE distributions (Figures S5-S9); plots of kinematic viscosity and oxidation rating (Figure S10); tabulated kinematic viscosity and oxidation rating data (Table S5); unique species observed at $168 \mathrm{~h}$ (Figures S11 and S12); enlarged sections of mass spectra (Figures S13 and S14) (PDF)

\section{AUTHOR INFORMATION}

\section{Corresponding Author}

Mark P. Barrow - Department of Chemistry, University of Warwick, Coventry CV4 7AL, United Kingdom; ○ orcid.org/0000-0002-6474-5357; Email: m.p.barrow@ warwick.ac.uk

\section{Authors}

Hugh E. Jones - Molecular Analytical Sciences Centre for Doctoral Training and Department of Chemistry, University of Warwick, Coventry CV4 7AL, United Kingdom

Diana Catalina Palacio Lozano - Department of Chemistry, University of Warwick, Coventry CV4 7AL, United

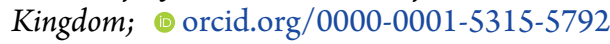

Chris Huener - Lubrizol Ltd., Derby DE56 4AN, United Kingdom

Mary J. Thomas - Molecular Analytical Sciences Centre for Doctoral Training and Department of Chemistry, University of Warwick, Coventry CV4 7AL, United Kingdom; (1) orcid.org/0000-0002-6744-5413

David J. Aaserud - The Lubrizol Corporation, Wickliffe, Ohio 44092, United States

J. Corinne DeMuth - The Lubrizol Corporation, Wickliffe, Ohio 44092, United States

Mathew P. Robin - Lubrizol Ltd., Derby DE56 4AN, United Kingdom

Complete contact information is available at:

https://pubs.acs.org/10.1021/acs.energyfuels.1c01240

\section{Notes}

The authors declare no competing financial interest.

\section{ACKNOWLEDGMENTS}

The authors thank the Engineering and Physical Sciences Research Council (EPSRC) for PhD studentships through the EPSRC Centre for Doctoral Training in Molecular Analytical Science (Grant EP/L015307/1). The Newton Fund (reference number 275910721), Research Agreement No. 5211770 UISICP, and COLCIENCIAS (Project FP44842-039-2015) are also thanked for providing funding. David Stranz (Sierra Analytics) is thanked for collaborative developments and access to Composer software. Lubrizol Ltd. is thanked for granting permission to publish.

\section{REFERENCES}

(1) Gallopoulos, N. E. Engine Oil Thickening in High-Speed Passenger Car Service. SAE Technol. Pap. Ser. 1970, 79, 1872-1887.

(2) Edmisten, W. C.; Peterson, J. V.; Sholts, R. A. Three Aspects of Motor Oil Thickening. SAE Technol. Pap. Ser. 1970, DOI: 10.4271/ 700509.

(3) Maleville, X.; Faure, D.; Legros, A.; Hipeaux, J. C. Oxidation of Mineral Base Oils of Petroleum Origin: The Relationship between
Chemical Composition, Thickening, and Composition of Degradation Products. Lubr. Sci. 1996, 9 (1), 1-60.

(4) Bouillon, V. Overview of Oxidation Laboratory Tests on Industrial Lubricants. Tribol. und Schmierungstechnik 2018, 65 (2), $38-46$.

(5) Mortier, R. M. In Chemistry and Technology of Lubricants; Mortier, R. M., Fox, M. F., Orszulik, S. T., Eds.; Springer Netherlands: Dordrecht, 2010.

(6) Adhvaryu, A.; Erhan, S. Z.; Sahoo, S. K.; Singh, I. D. ThermoOxidative Stability Studies on Some New Generation API Group II and III Base Oils. Fuel 2002, 81 (6), 785-791.

(7) Korcek, S.; Jensen, R. K. Relation between Base Oil Composition and Oxidation Stability at Increased Temperatures. ASLE Trans. 1976, 19 (2), 83-94.

(8) Ray, J. ICIS Global Base Oil Scenarios, 2019.

(9) Mang, T.; Lingg, G. Base Oils. In Lubricants and Lubrication; Wiley-VCH Verlag GmbH \& Co. KGaA: Weinheim, Germany, 2007; pp 34-62.

(10) Braun, J. Additives. In Lubricants and Lubrication; Wiley-VCH Verlag GmbH \& Co. KGaA: Weinheim, Germany, 2017; pp 88-118.

(11) Zuidema, H. H. Oxidation of Lubricating Oils. Chem. Rev. 1946, 38 (2), 197-226.

(12) Qian, X.; Xiang, Y.; Shang, H.; Cheng, B.; Zhan, S.; Li, J. Thermal-Oxidation Mechanism of Dioctyl Adipate Base Oil. Friction 2016, 4 (1), 29-38.

(13) Frauscher, M.; Besser, C.; Allmaier, G.; Dörr, N. Oxidation Products of Ester-Based Oils with and without Antioxidants Identified by Stable Isotope Labelling and Mass Spectrometry. Appl. Sci. 2017, 7 (4), 396.

(14) Kohler, M.; Heeb, N. V. Characterization of Ageing Products of Ester-Based Synthetic Lubricants by Liquid Chromatography with Electrospray Ionization Mass Spectrometry and by Electrospray Ionization (Tandem) Mass Spectrometry. J. Chromatogr. A 2001, 926 (1), 161-165.

(15) Cerny, J.; Strnad, Z.; Sebor, G. Composition and Oxidation Stability of SAE 15W-40 Engine Oils. Tribol. Int. 2001, 34 (2), 127134.

(16) Adhvaryu, A.; Perez, J. M.; Singh, I. D.; Tyagi, O. S. Spectroscopic Studies of Oxidative Degradation of Base Oils. Energy Fuels 1998, 12 (6), 1369-1374.

(17) Zdrodowski, R.; Gangopadhyay, A.; Anderson, J. E.; Ruona, W. C.; Uy, D.; Simko, S. J. Effect of Biodiesel (B20) on Vehicle-Aged Engine Oil Properties. SAE Int. J. Fuels Lubr. 2010, 3 (2), 2010-012103.

(18) Ball, J. C.; Anderson, J. E.; Duckworth, J. A.; Uy, D.; Wallington, T. J. Oxidation of Soybean Biodiesel Fuel in Diesel Engine Oils. SAE Int. J. Fuels Lubr. 2019, DOI: 10.4271/04-12-030015.

(19) Devlin, C. C.; Passut, C. A.; Campbell, R. L.; Jao, T. C. Biodiesel Fuel Effect on Diesel Engine Lubrication. SAE Tech. Pap. Ser. 2008, DOI: $10.4271 / 2008-01-2375$.

(20) Ball, J. C.; Anderson, J. E.; Pivesso, B. P.; Wallington, T. J. Oxidation and Polymerization of Soybean Biodiesel/Petroleum Diesel Blends. Energy Fuels 2018, 32 (1), 441-449.

(21) Pullen, J.; Saeed, K. An Overview of Biodiesel Oxidation Stability. Renewable Sustainable Energy Rev. 2012, 16 (8), 5924-5950.

(22) Kuti, O. A.; Yang, S. Y.; Hourani, N.; Naser, N.; Roberts, W. L.; Chung, S. H.; Sarathy, S. M. A Fundamental Investigation into the Relationship between Lubricant Composition and Fuel Ignition Quality. Fuel 2015, 160, 605-613.

(23) Kassler, A.; Pittenauer, E.; Doerr, N.; Allmaier, G. Development of an Accelerated Artificial Ageing Method for the Characterization of Degradation Products of Antioxidants in Lubricants by Mass Spectrometry. Eur. J. Mass Spectrom. 2019, 25, 300.

(24) Ahmad, I.; Ullah, J.; Ishaq, M.; Khan, H.; Khan, R.; Ahmad, W.; Gul, K. Oxidative Stability of the Plain and Additized Mineral Base Oil Samples Monitored through Gas Chromatography-Mass Spectrometry. Energy Fuels 2015, 29 (10), 6522-6528. 
(25) Barrère, C.; Hubert-Roux, M.; Afonso, C.; Racaud, A. Rapid Analysis of Lubricants by Atmospheric Solid Analysis Probe-Ion Mobility Mass Spectrometry. J. Mass Spectrom. 2014, 49 (8), 709715 .

(26) Ahmad, I.; Ullah, J.; Ishaq, M.; Khan, H.; Khan, R.; Ahmad, W.; Gul, K. Oxidative Stability of Base Lubricant Oil Monitored by Gas Chromatography-Mass Spectrometry: Influence of Sawdust-Derived Antioxidants. Energy Fuels 2017, 31 (7), 7653-7661.

(27) Kassler, A.; Pittenauer, E.; Doerr, N.; Allmaier, G. UltrahighPerformance Liquid Chromatography/Electrospray Ionization Linear Ion Trap Orbitrap Mass Spectrometry of Antioxidants (Amines and Phenols) Applied in Lubricant Engineering. Rapid Commun. Mass Spectrom. 2014, 28 (1), 63-76.

(28) Hourani, N.; Muller, H.; Adam, F. M.; Panda, S. K.; Witt, M.; Al-Hajii, A. A.; Sarathy, S. M. Structural Level Characterization of Base Oils Using Advanced Analytical Techniques. Energy Fuels 2015, 29 (5), 2962-2970.

(29) Besser, C.; Agocs, A.; Ronai, B.; Ristic, A.; Repka, M.; Jankes, E.; McAleese, C.; Dörr, N. Generation of Engine Oils with Defined Degree of Degradation by Means of a Large Scale Artificial Alteration Method. Tribol. Int. 2019, 132, 39-49.

(30) Jin, C.; Viidanoja, J.; Li, M.; Zhang, Y.; Ikonen, E.; Root, A.; Romanczyk, M.; Manheim, J.; Dziekonski, E.; Kenttämaa, H. I. Comparison of Atmospheric Pressure Chemical Ionization and Field Ionization Mass Spectrometry for the Analysis of Large Saturated Hydrocarbons. Anal. Chem. 2016, 88 (21), 10592-10598.

(31) Godoy, A. T.; Pereira, G. G.; Ferreira, L. L.; Cunha, I. B. S.; Barrera-Arellano, D.; Daroda, R. J.; Eberlin, M. N.; Alberici, R. M. Biodiesel Oxidation Monitored by Ambient Desorption/Ionization Mass Spectrometry. Energy Fuels 2013, 27 (12), 7455-7459.

(32) Cho, E.; Witt, M.; Hur, M.; Jung, M. J.; Kim, S. Application of FT-ICR MS Equipped with Quadrupole Detection for Analysis of Crude Oil. Anal. Chem. 2017, 89 (22), 12101-12107.

(33) Palacio Lozano, D. C.; Gavard, R.; Arenas-Diaz, J. P.; Thomas, M. J.; Stranz, D. D.; Mejía-Ospino, E.; Guzman, A.; Spencer, S. E. F.; Rossell, D.; Barrow, M. P. Pushing the Analytical Limits: New Insights into Complex Mixtures Using Mass Spectra Segments of Constant Ultrahigh Resolving Power. Chem. Sci. 2019, 10 (29), 6966-6978.

(34) Molnárné Guricza, L.; Schrader, W. Electrospray Ionization for Determination of Non-Polar Polyaromatic Hydrocarbons and Polyaromatic Heterocycles in Heavy Crude Oil Asphaltenes. J. Mass Spectrom. 2015, 50 (3), 549-557.

(35) Zhang, S.; Huo, J.; Sun, X.; Yang, F.; Wang, P.; Wu, J.; Zhang, Y.; Shi, Q. Molecular Composition Reveals Unique Rheological Property of Karamay Heavy Crude Oil. Energy Fuels 2021, 35 (1), 473-478.

(36) Hawkes, J. A.; D’Andrilli, J.; Agar, J. N.; Barrow, M. P.; Berg, S. M.; Catalán, N.; Chen, H.; Chu, R. K.; Cole, R. B.; Dittmar, T.; Gavard, R.; Gleixner, G.; Hatcher, P. G.; He, C.; Hess, N. J.; Hutchins, R. H. S.; Ijaz, A.; Jones, H. E.; Kew, W.; Khaksari, M.; Palacio Lozano, D. C.; Lv, J.; Mazzoleni, L. R.; Noriega-Ortega, B. E.; Osterholz, H.; Radoman, N.; Remucal, C. K.; Schmitt, N. D.; Schum, S. K.; Shi, Q.; Simon, C.; Singer, G.; Sleighter, R. L.; Stubbins, A.; Thomas, M. J.; Tolic, N.; Zhang, S.; Zito, P.; Podgorski, D. C. An International Laboratory Comparison of Dissolved Organic Matter Composition by High Resolution Mass Spectrometry: Are We Getting the Same Answer? Limnol. Oceanogr.: Methods 2020, 18 (6), 235-258.

(37) Smith, D. F.; Podgorski, D. C.; Rodgers, R. P.; Blakney, G. T.; Hendrickson, C. L. 21 T FT-ICR Mass Spectrometer for UltrahighResolution Analysis of Complex Organic Mixtures. Anal. Chem. 2018, 90 (3), 2041-2047.

(38) Terrell, E.; Garcia-Perez, M. Novel Strategy to Analyze Fourier Transform Ion Cyclotron Resonance Mass Spectrometry Data of Biomass Pyrolysis Oil for Oligomeric Structure Assignment. Energy Fuels 2020, 34 (7), 8466-8481.

(39) Palacio Lozano, D. C.; Ramírez, C. X.; Sarmiento Chaparro, J. A.; Thomas, M. J.; Gavard, R.; Jones, H. E.; Cabanzo Hernández, R.; Mejia-Ospino, E.; Barrow, M. P. Characterization of Bio-Crude
Components Derived from Pyrolysis of Soft Wood and Its Esterified Product by Ultrahigh Resolution Mass Spectrometry and Spectroscopic Techniques. Fuel 2020, 259, 116085.

(40) Hita, I.; Cordero-Lanzac, T.; Kekälaïnen, T.; Okafor, O.; Rodríguez-Mirasol, J.; Cordero, T.; Bilbao, J.; Jänis, J.; Castano, P. InDepth Analysis of Raw Bio-Oil and Its Hydrodeoxygenated Products for a Comprehensive Catalyst Performance Evaluation. ACS Sustainable Chem. Eng. 2020, 8 (50), 18433-18445.

(41) Palacio Lozano, D. C.; Thomas, M. J.; Jones, H. E.; Barrow, M. P. Petroleomics: Tools, Challenges, and Developments. Annu. Rev. Anal. Chem. 2020, 13 (1), 405-430.

(42) Benassi, M.; Berisha, A.; Romão, W.; Babayev, E.; Römpp, A.; Spengler, B. Petroleum Crude Oil Analysis Using Low-Temperature Plasma Mass Spectrometry. Rapid Commun. Mass Spectrom. 2013, 27 (7), 825-834.

(43) Fernandes, A. M. A. P.; El-Khatib, S.; Cunha, I. B. S.; Porcari, A. M.; Eberlin, M. N.; Silva, M. J.; Silva, P. R.; Cunha, V. S.; Daroda, R. J.; Alberici, R. M. Chemical Characterization of Jatropha Curcas L. Seed Oil and Its Biodiesel by Ambient Desorption/Ionization Mass Spectrometry. Energy Fuels 2015, 29 (5), 3096-3103.

(44) ASTM D7279-20, Standard Test Method for Kinematic Viscosity of Transparent and Opaque Liquids by Automated Houillon Viscometer, 2020.

(45) ASTM D7946-19, Standard Test Method for Initial PH (i-PH)Value of Petroleum Products, 2019.

(46) DIN 51453. Testing of Lubricants - Determination of Oxidation and Nitration of Used Motor Oils - Infrared Spectrometric Method, 2010.

(47) Gavard, R.; Rossell, D.; Spencer, S. E. F.; Barrow, M. P. Themis: Batch Preprocessing for Ultrahigh-Resolution Mass Spectra of Complex Mixtures. Anal. Chem. 2017, 89 (21), 11383-11390.

(48) Gavard, R.; Jones, H. E.; Palacio Lozano, D. C.; Thomas, M. J.; Rossell, D.; Spencer, S. E. F. F.; Barrow, M. P. KairosMS: A New Solution for the Processing of Hyphenated Ultrahigh Resolution Mass Spectrometry Data. Anal. Chem. 2020, 92 (5), 3775-3786.

(49) R Core Team. R: A Language and Environment for Statistical Computing. Vienna, Austria, 2020.

(50) Krassowski, M. Krassowski/Complex-Upset V., 2021.

(51) Huba, A. K.; Huba, K.; Gardinali, P. R. Understanding the Atmospheric Pressure Ionization of Petroleum Components: The Effects of Size, Structure, and Presence of Heteroatoms. Sci. Total Environ. 2016, 568, 1018-1025.

(52) Neto, R.; Lima, D. O.; Pinheiro, T. D. S.; Almeida, F.; Dantas, T. N. C.; Dantas, M. S. G.; Arau, M. A. S.; Cavalcante, L.; Azevedo, D. C. S. Thermo-Oxidative Stability of Mineral Naphthenic Insulating Oils : Combined Effect of Antioxidants and Metal Passivator. Ind. Eng. Chem. Res. 2004, 43, 7428-7434.

(53) Adhvaryu, A.; Sharma, Y. K.; Singh, I. D. Studies on the Oxidative Behavior of Base Oils and Their Chromatographic Fractions. Fuel 1999, 78 (11), 1293-1302.

(54) van Agthoven, M. A.; Lam, Y. P. Y.; O’Connor, P. B.; Rolando, C.; Delsuc, M. A. Two-Dimensional Mass Spectrometry: New Perspectives for Tandem Mass Spectrometry. Eur. Biophys. J. 2019, 48 (3), 213-229.

(55) Hsu, S. M.; Ku, C. S.; Lin, R. S. Relationship between Lubricating Basestock Composition and the Effects of Additives on Oxidation Stability. SAE Technol. Pap. Ser. 1982, DOI: 10.4271/ 821237.

(56) Kramer, D. C.; Ziemer, J. N.; Cheng, M. T.; Fry, C. E.; Reynolds, R. N.; Lok, B. K.; Sztenderowicz, M. L.; Krug, R. R. Influence of Group II \& III Base Oil Composition on VI and Oxidation Stability. NLGI Annu. Meet. 1999, 1-17.

(57) Fang, H. L.; McCormick, R. L. Spectroscopic Study of Biodiesel Degradation Pathways. SAE Tech. Pap. Ser. 2006, 724, 776-790.

(58) Lex, A.; Gehlenborg, N.; Strobelt, H.; Vuillemot, R.; Pfister, H. UpSet: Visualization of Intersecting Sets. IEEE Trans. Vis. Comput. Graph. 2014, 20 (12), 1983-1992.

(59) Rüger, C. P.; Schwemer, T.; Sklorz, M.; O’Connor, P. B.; Barrow, M. P.; Zimmermann, R. Comprehensive Chemical Compar- 
ison of Fuel Composition and Aerosol Particles Emitted from a Ship

Diesel Engine by Gas Chromatography Atmospheric Pressure Chemical Ionisation Ultra-High Resolution Mass Spectrometry with

Improved Data Processing Routines. Eur. J. Mass Spectrom. 2017, 23 (1), 28-39.

(60) Kim, D.; Kim, S.; Son, S.; Jung, M.-J.; Kim, S. Application of Online Liquid Chromatography 7 T FT-ICR Mass Spectrometer Equipped with Quadrupolar Detection for Analysis of Natural Organic Matter. Anal. Chem. 2019, 7690-7697. 